\title{
Estudios agrarios críticos: tierras, semillas, soberanía alimentaria y derechos de las y los campesinos
}

\author{
Marc Edelman \\ Quito: Instituto de Altos Estudios Nacionales (IAEN) \\ 2016, 132 páginas
}

\section{FELIPE ROJAS ARIAS*}

Universidad del Rosario

El libro Estudios agrarios críticos: tierras, semillas, soberanía alimentaria y derechos de las y los campesinos es una compilación de ensayos preparada por el antropólogo Marc Edelman para un curso que dictó en el Instituto de Altos Estudios Nacionales en Ecuador en el 2016. Más que una aproximación detallada al mundo agrario, es una invitación a la discusión de varios aspectos de investigación y reflexión, mediante críticas provocadoras que socavan lugares comunes en cuatro campos: el acaparamiento de tierras, las semillas, la soberanía alimentaria y los derechos de los campesinos.

La base de sus planteamientos está en su definición de los estudios agrarios críticos. Edelman sostiene que estos tienen como fundamento tres aspectos: la identificación con y la simpatía por los sectores desfavorecidos y la búsqueda de justicia social, el análisis basado en lo empírico y en la economía política, y una toma de posición que no implica pérdida de objetividad. Por definición, estos estudios son agrarios y no campesinos, ya que el mundo rural está habitado por e involucra a otra serie de actores, como grupos étnicos, trabajadores de plantaciones, terratenientes, pastores nómadas, comerciantes, entre otros. Y son críticos porque cuestionan los paradigmas dominantes del desarrollo rural, del derecho, de la raza, de la producción del conocimiento y de las políticas macroeconómicas de las últimas décadas.

Antropólogo e historiador de la Universidad del Rosario. Máster en Antropología de la Universidad de los Andes. rojasariasfelipe@gmail.com. 
El acaparamiento es un tema central en los estudios agrarios de los últimos años. Este concepto se relaciona con la relectura hecha por el geógrafo David Harvey de la noción de acumulación originaria de Marx (Arias y Caicedo 2016). El acaparamiento por desposesión se refiere a los procesos de acumulación de tierras y otros recursos, en el marco de conflictos armados y de proyectos extractivos, hidroeléctricos y agroindustriales, que afectan la configuración territorial y económica del mundo agrario y las formas de vida de sus habitantes. Como lo muestran Arias y Caicedo (2016), el acaparamiento se ha acelerado desde el 2008, por lo que es un problema actual urgente de estudiar. Sin embargo, no es un fenómeno de hoy. Por el contrario, como lo sugiere Edelman, debe entenderse como un hecho histórico de dominación sobre el mundo agrario por sectores económicos y políticos hegemónicos. El análisis del acaparamiento como proceso histórico permite entender los problemas del mundo agrario en el pasado y en el presente.

Los estudios agrarios críticos examinan el acaparamiento como un proceso social y como un objeto de estudio de las ciencias sociales. En el primer capítulo, Edelman propone siete dimensiones que todo investigador debe tener en cuenta a la hora de estudiarlo: 1) la historicidad del acaparamiento de tierras. 2) Las distintas escalas del acaparamiento - que generalmente se refiere a grandes extensiones de tierra-, para no dejar de lado el despojo menos llamativo, más silencioso y de menor escala en términos cuantitativos. El autor insiste en la importancia de considerar que la tierra no es el único recurso u objeto de acaparamiento y que es necesario observar las escalas de los capitalistas involucrados en este proceso. 3) La incidencia de la caída de los precios de las materias primas en la generación de diversos procesos de acaparamiento. 4) El papel de los actores nacionales en los procesos de acaparamiento, ya que los extranjeros no son los únicos que ejercen o participan en esta práctica. 5) Las diversas reacciones de los grupos campesinos ante el acaparamiento, incluyendo las perspectivas generacionales y de género. 6) Las múltiples y cada vez más complejas dimensiones que juega la financiarización en el acaparamiento de tierras. 7) El acaparamiento para fines no agrícolas.

El segundo capítulo complejiza los procesos alrededor de la privatización, el mejoramiento y la certificación de las semillas. Lejos de afirmar que los derechos de propiedad intelectual siempre han sido mecanismos de despojo y de generación de dependencia de los campesinos hacia las corporaciones, Edelman muestra que, en su origen, los campesinos participaron en estas iniciativas. Si bien la situación de la producción y comercialización de las semillas se transformó con el ingreso del capital privado y la consolidación de la industria semillera, el autor considera que el origen participativo de la certificación de semillas es 
una oportunidad para empoderar a los campesinos y tener en cuenta sus conocimientos, sin restarles autonomía y derechos sobre este recurso. Incluso, aunque parte de los marcos regulatorios sobre la propiedad intelectual y el mejoramiento de semillas son contradictorios y favorables para las corporaciones, algunos de ellos pueden dar pie a la protección de los pequeños productores rurales, la biodiversidad y los conocimientos locales.

La discusión sobre la soberanía alimentaria es el eje del tercer capítulo. Existe un lugar común entre los movimientos sociales y la academia al considerar que la soberanía alimentaria es un concepto que surge en la década de los noventa, en particular, en el seno de La Vía Campesina, y que es diametralmente opuesto al de la seguridad alimentaria. Edelman propone lo contrario. En su análisis e historización demuestra que este concepto ambiguo tiene origen en los años ochenta en un programa de alimentación del Gobierno mexicano, que no buscaba solamente la autosuficiencia alimentaria sino también el control nacional de las cadenas de producción, con el fin de reducir la dependencia de los productos extranjeros. Por otro lado, el autor propone que los conceptos de seguridad y soberanía alimentaria han tenido traslapes en distintos momentos históricos.

Aunque Edelman no especifica qué entiende por soberanía alimentaria, sí plantea una serie de críticas del concepto que son fundamentales para comprender su perspectiva sobre este. En especial, se pregunta por quién es el soberano de la soberanía alimentaria, quién debe imponer las regulaciones de la producción y las exportaciones, y por qué se limita la importación de productos que por las condiciones climáticas no pueden ser producidos en el lugar donde son consumidos. Sostiene, además, que las regulaciones a la producción que proponen algunos defensores de la soberanía alimentaria pueden incluso limitar la acción de los productores campesinos, al restringir las exportaciones e importaciones y controlar los tamaños y tipos de explotaciones agrícolas, lo cual va en contravía del concepto mismo.

Finalmente, Edelman ofrece un contexto histórico del proyecto sobre la declaración de los derechos de los campesinos ${ }^{1}$ que se encuentra en discusión en las Naciones Unidas. En su reconstrucción de la iniciativa señala el origen, la trayectoria y las problemáticas de esta propuesta y sus consecuencias directas en las políticas agrarias de varios países de América Latina. Aunque el hecho de que tal proyecto sea una declaratoria y no un convenio, que sí sería vinculante para los países miembros de la ONU, sostiene que sus efectos positivos son

\footnotetext{
1 Proyecto de declaración sobre los derechos de los campesinos y de otras personas que trabajan en las zonas rurales. Para mayor información véase http://www.ohchr.org/EN/HRBodies/HRC/ RuralAreas/Pages/4thSession.aspx. [N. de la E.].
} 
visibles cuando algunos Estados lo han tratado de aplicar o incorporar en su legislación. Para mostrar los posibles alcances de esta declaratoria, el autor se vale de ejemplos en México, Perú, Honduras y Colombia, donde se ha intentado poner en práctica algunos de sus principios en ciertas políticas públicas. En el caso de Colombia, hace alusión a las intenciones de senadores de declarar los derechos de los campesinos mediante la modificación del artículo 64 de la Constitución Política de $1991^{2}$, teniendo como impulso el contexto actual del posconflicto. Tal propuesta es central en un momento en el que miembros de la academia y diversas organizaciones campesinas cuestionan lo excluyente que resulta el marco legal multicultural para los campesinos, quienes ven en la declaratoria una posibilidad de igualdad y garantía en derechos.

El texto de Edelman es de gran importancia por dos razones principales. Primero, su amplia trayectoria de trabajo histórico, etnográfico y bibliográfico en temas agrarios en distintas escalas sustenta sus argumentos. Este conocimiento invita a los investigadores a realizar estudios historizados y contextuales de los problemas del mundo agrario. Segundo, los temas y perspectivas que propone para entender, pensar y transformar los mundos agrarios contemporáneos son relevantes en el marco de la creciente lucha en contra de los modelos de reprimarización de la economía asociados a la extracción de materias primas y la explotación agroindustrial. Sus ensayos abren la puerta a nuevas dimensiones, matices y aristas de los dinámicos y contenciosos escenarios rurales, y señalan novedosos caminos de interpretación y acción política al cuestionar lugares comunes en el plano de la teoría y de la práctica.

En el contexto colombiano, los aportes del autor son útiles para examinar los vínculos entre el acaparamiento de recursos naturales vitales y las luchas del movimiento agrario por un modelo de desarrollo alternativo, así como por el reconocimiento de derechos diferenciales para el campesinado en un marco multicultural neoliberal. En la actual coyuntura de los acuerdos de paz de La Habana entre el Estado y la guerrilla de las FARC, los planteamientos de Edelman son un referente de consulta frente a la Reforma Rural Integral y los retos que plantea para la reestructuración del mundo agrario en temas como el acceso y distribución de la tierra, la democratización rural y la seguridad alimentaria con participación de la economía familiar. En mi opinión, Edelman es consciente de que la declaratoria de derechos de los campesinos y los demás asuntos abordados en su texto son fundamentales en los nuevos escenarios del posacuerdo en Colombia.

2 El proyecto de ley propuesto por el senador Alberto Castilla, del partido Polo Democrático Alternativo, busca reformar el artículo 64 de la Constitución con el objetivo de que se reconozca al campesino como sujeto de especial protección y su derecho a la territorialidad. 


\section{Referencias}

Arias, Julio y Alhena Caicedo. 2016. "Aproximaciones al despojo desde Colombia: despojo y antropología hoy”. Revista Colombiana de Antropología 52 (2): 7-15. https://revistas.icanh. gov.co/index.php/rca/article/view/1/1. 